Motrivivência $\quad$ Ano XX, $\quad$ No 31, P. 256-273 $^{\circ}$ Dez./2008

\title{
Educação Física aberta à experiência - uma concepção didática em discussão. Reiner Hildebrandt-Stramann [Rio de Janeiro: Imperial Novo Milênio, 2009]
}

\author{
Jozilma Batalha-Lemke
}

\begin{abstract}
Resumo
Nesta resenha, apresentamos a obra de Hildebrandt-Stramann, com uma postura de diálogo entre suas reflexões teóricas e, os modelos práticos descritos, tendo por base sua 'concepção aberta à experiência', no contexto didático-pedagógico da Educação Física. Com esse objetivo, destacamos suas particularidades referente a esta temática, que vem numa hora oportuna, primeiro por sua atualização em face às discussões que permeiam os conteúdos da Educação Física e, segundo, por jorrar luz sobre a tensa relação entre as teorias e praticas dos dilemas

Abstract

In this paper, we introduce the Hildebrandt-Stramann, with his dialogue posture between his theorical reflections and, his described practical model, based on his "conception open to experience" in Physical Education didacticalpedagogical context. With this goal, we highlight his features concerning to this thematic, which comes in a timely time, first by its updating face to the discussions which permeate the Physical Education content and, second, by spread light upon the tense relation between the theories and practical of the inserted dilemmas in the "promotion
\end{abstract}

1 Doutoranda no Instituto da Ciência do Esporte e da Pedagogia do Movimento da Universidade Técnica de Braunschweig, Alemanha. Mestra em Ciências do Ambiente e Políticas Públicas Ambientais (UFAM/AM). Especialista em Psicomotricidade (UCM/RJ) Graduada em Educação Física (UFAM/AM)

Contato: jozibps@gmail.com 
inseridos nas propostas da 'promoção do esporte' ou de uma 'transformação da Educação Física na escola'.

Palavras-Chaves: Educação Física; Experiência; Formação; Movimento e Salutogênese. of sport" proposal. Or of one Physical Education transformation in school.

Keywords: Physical Education; Experience; Movement; Salutogenesis.

\section{Educação Física encenada na atual 'crise ambiental': (des) necessária e (des)moralizada!?}

No cenário atual de crise ambienta $/ 2$ que permeia a sociedade contemporânea, Leonardo Boff (2008) denuncia a falta do saber cuidar, argumentando que a realidade concreta, com seus cheiros, cores, frios, calores, pesos, resistências e contradições é mediada pela imagem virtual que é somente imagem e que, o 'mundo virtual' criou um novo habitat para os seres humanos, caracterizados pelo encapsulamento sobre si mesmo e pela falta do toque, do tato e do contato humano (p.11). Consideramos por isto, a urgência de se olhar à realidade da vida cotidiana ${ }^{3}$, como uma realidade de relação e, não de isolamento, ou seja, que considere a relação corpo e ambiente como interdependente em sua prática social e individual.

Neste cenário, é imperioso se discutir o contexto da Educação Física e do esporte em face de seus 'paradigmas' com relação ao corpo, movimento, educação e saúde. E, a obra de Hildebrandt-Stramann surge como uma alternativa de se pensar e, de se fazer atuar nesta sociedade que se 'revela' em dois mundo: o 'mundo virtual' e, o 'mundo-vivido'. Nesta perspectiva a obra traz reflexões a respeito do termo 'experiência' como categoria didática central que se relaciona com esta realidade da vida cotidiana, especificamente, no ambiente escolar, bem como, discuti a Educação Física por meio de diferentes perspectivas, em oito capítulos reunidos em 123 páginas.

2 Leff, E. (2001) nos faz alusão que a crise ambiental anuncia o limite do projeto economicista que tem desencadeado uma "mania de crescimento", de uma produção sem limite.

3 Berger \& Luckmann (2005) assinalam que a realidade da vida cotidiana apresenta-se como um mundo de que se participa juntamente com outros homens. Se estar sozinho no mundo dos sonhos, mas o mundo da vida cotidiana é tão real para os outros quanto para si mesmo. Em que não se pode existir na vida cotidiana sem estar continuamente em interação e comunicação com os outros e o ambiente. 
As discussões partem dos fundamentos teóricos do autor nas disciplinas científicas da fenomenologia, da antropologia e da pedagogia crítica que, se configuram nas descrições nesta obra sobre: o movimentar-se, a 'experiência', o processo de ensino-aprendizagem por oficinas, o aprender diante de problemas e, a escola como uma 'Escola móvel'. Além, de abordar o relacionamento entre o homem e a natureza, a formação de professores e o conceito da pratica de movimento salutogenética. Todos estes textos possuem o objetivo de contribuir com as discussões didático-pedagógica na área da Educação Física.

Assim, o cenário descrito nesta obra, nos estimula a reflexões pedagógicas diante da realidade da Educação Física em nível Internacional e, sobretudo, as ações cooperadoras realizadas - e, não transmitidas e copiadas - para uma Educação Física Brasileira. Educação Física esta, que não só se evidencie na realização de eventos esportivos (Jogos PanAmericanos, Copa do Mundo, Olimpíada, etc.) e pela ampliação de cursos, mas acima de tudo, que (re) direcione seu interesse a realidade sócio-educativa-ecológica da escola.

\section{Educação Física orientada ao ser humano que se movimen- ta no mundo...}

Com uma medida certa de criticidade e sensibilidade dialética, Hildebrandt-Stramann argumenta em seu primeiro capítulo a necessidade de refletir os conceitos sobre: educação, desenvolvimento, movimento, ensino e escola, como meios de se discutir uma resposta à pergunta: Quais os rumos da Educação Física?

Assim, abre a discussão sobre educação como a idéia de que alguém seja educado por um outro - pelo professor - é um engano. O educador não pode dispor da ação de alguém, isto é, não é possível transformar a intenção do professor em ação no aluno (p.14), e por isto, a educação deve possuir um significado de se promover a autoeducação, a partir de um diálogo com o mundo da vida ${ }^{4}$. Nesta concepção de educação torna-se necessário refletir as relações do aluno - decidido e disposto - com as mudanças de ordem política,

4 Para o autor este "mundo da vida" também são os horizontes de experiência significativos autoeducadoras 
histórico-social, cultural e ecológica interdependentes no seu cotidiano de vida. Para tanto, sugere-se uma corrente de atos de comunicação ${ }^{5-}$ na relação professor-aluno em suas ações didático-pedagógicas.

Partindo da pergunta: quais são as tarefas que podem dar apoio ao adolescente? $\mathrm{O}$ autor discorre sobre o conceito de desenvolvimento, tomando uma posição antropológico-social de que o indivíduo gera seu desenvolvimento no próprio agir, isto é, no confronto com a realidade interior, biopsíquica, de um lado, e com a realidade externa, ecológico-social, do outro (p. 15-16). Esta tomada de posição do autor quanto ao conceito de desenvolvimento, reforça a perspectiva de relação existente entre as práticas sociais e a historia e condições de vida do aluno, como algo necessário nas ações didáticopedagógicas no ambiente escolar.

Com a afirmação de que a Educação Física tem como meta o melhor desenvolvimento de todos os alunos (p.18), o autor interpreta as concepções de esporte e movimento tomando por base o ato de movimentar-se e, não as formas padronizadas do movimento. O que fundamenta a diferença entre movimento e movimento próprio são pessoas se movimentando e, o significado do movimento em si. Sendo essencial este pensar na superação da aplicação imediata das análises clássicas do movimento do esporte pela biomecânica. Nesta diferença de pensar o movimento, observar-se a posição fenomenológica do movimento tomada pelo autor, quando o mesmo apóia-se num conceito dialógico e, nos diz que:

"movimentar-se é um comportar-se significante, com referência a cada situação específica de movimento individual; é a ação na qual o mundo e as coisas nele contidas podem ser compreendidos como um todo recíproco: um mundo de saltar, de montar, de balançar. Movimentar-se é uma forma espontânea de compreensão do mundo em ação" (p. 19)

Para mostrar como podem ser configuradas as condições necessárias a autoeducação, ao desenvolvimento de uma proposta ecológico-social e, o resgate do movimento como diálogo no contexto escolar, o autor sugere uma concepção de escola compreendida

5 O autor recomenda que os educadores devem iniciar este "ato de comunicação" para que o aluno possa por si decidir a executar ou não determinados desafios antes de assumi-los. 
como Escola Móvel ${ }^{6}$. Descreve duas suposições básicas quanto à este termo: a primeira de que os esforços educativos do professor estão integrados no contexto socio-ecológico da vida escolar (p.21) e, a segunda de que a escola deveria caracterizarse como espaço de vida, de experiência e, também, de movimento, considerando esse movimentar-se não só na Educação Física, mas em todo o espaço escolar (p.21).

\section{Educação Física centralizada na experiência para / pelo movimentar-se...}

No segundo capitulo, Hildebrandt-Stramann esclarece que a base pedagógica da aprendizagem motora é a experiência corporal, denuncia que as técnicas motoras não são experimentáveis para as crianças (p.26-27) e, desenvolve cinco teses para nos afirmar que a experiência é uma categoria central na aprendizagem do movimento.

$1^{\mathrm{a}}$. A experiência é autêntica. O autor cita dois exemplos que esclarece a autonomia dos motivos de movimento da criança e conseqüentemente a autenticidade da experiência: o futebol de rua e as cenas de breakdance, argumentan- do que estas ações devem referir-se unicamente a esses aprendizes, pois somente assim podem levar a um sentido e, que a aprendizagem organizada como cópia de valores teóricos prescritos com o máximo de feedback externo é pouco autêntica. (p.27)

$2^{\mathrm{a}}$. A experiência tem caráter de diálogo. O autor afirma que o movimento baseado na experiência sempre liga dois pólos a um relacionamento mútuo, do qual o movimento recebe seu estímulo e seu interesse: isso faz com que aquele que se movimenta se comunique com seu meio ambiente material e social (p.27).

$3^{\mathrm{a}}$. As experiências são reações da ação efetiva. O autor enfatiza que a experiência não é uma fase lúdica preliminar de uma aprendizagem correta e nem um experimentar sem compromisso, mas sim um comprometimento com temas e tarefas de movimento (p.28). E complementa que, somente pela ação efetiva as experiências se tornam próprias e são incorporadas, convertendo-se em possível apoio ao indivíduo no futuro (p.28).

$4^{\mathrm{a}}$. O objeto da experiência é a incorporação do novo e do desconhecido. O autor reconhece a importância de se sair das rotinas

6 Para o autor, é uma escola que reflete, conscientemente, o processo de desenvolvimento de uma cultura escolar e que, dentro do possível, o controla e o guia com suas próprias forças (p.22). 
habituais aplicadas no processo de ensino do movimento, e que as experiências já feitas podem ser confirmadas, diferenciadas e consolidadas (p.29).

$5^{\mathrm{a}}$. As experiências estão baseadas em auto-esboços projetivos. O autor elabora sua última Tese afirmando que o esboço de ação, a execução e a experiência formam uma unidade inseparável e que, a experiência corporal sempre integra o passado, o presente e o futuro ao contrário do mundo virtual - o que, de mais a mais, se torna decisivo para a vida e o cotidiano das crianças (p. 29).

É notório observar que por meio destas cinco Teses o autor denuncia - como também sutilmente o faz Boff citado no inicio desta resenha - problemáticas que permeiam o cotidiano de vida de crianças, jovens e adultos, reveladas em dois mundos: o "mundo virtual" e o usual e pronto, muitas vezes pobre de vivências no brinquedo e no esporte (p.29).

\section{Educação Física mediada pela aprendizagem por meio de pro- blemas e o ensinar e aprender em oficinas de movimento.}

Nos dois capítulos seguintes, isto é, o terceiro e quarto, o autor descreve junto com seus colegas da Universidade de Braunschweig da Alemanha, professores: Heike Beckmann e Klaus Wichmann, que para uma Educação Física orientada na experiência como categoria central na aprendizagem do movimento, necessita-se de dois importantes aspectos que são: uma aprendizagem direcionada por problemas e um ensinar e aprender em oficinas de movimento.

Nestes capítulos, fica claro que, também existem na Alemanha posições contrárias quanto às discussões didático-pedagógicas da Educação Física, onde os autores as descreve por meio de dois conceitos: um orientado na meta da aprendizagem (esporte) e o outro orientado na experiência (HildebrandtStramann, 2001). Concluem que a aprendizagem orientada no esporte é a de ensinar habilidades esportivas e da formação de pressupostos condicionais e coordenadores, com base teórico-informativa em que entende o aprendiz como um sistema de assimilação de informação e que com esse ensino seguese automaticamente o aprender e suas orientações seguem as séries de exercícios metodológicos de acordo com os princípios do 'fácil para o mais difícil' ou do 'simples ao complexo'. (p.31-32).

Assim, com exemplos de forma surpreendentemente dialético, desenvolvidos a partir do movi- 
mento do esporte, para a prática do conceito orientado na experiência, os autores consideram as quatro funções que o movimento humano compreende de acordo com FunkeWieneke: função instrumental, função social, função simbólica e função sensível (p.32-33). Reconhecem ainda em Martin Wagenschein - com seu princípio do ensino e do aprender genético - e em Paulo Freire - com sua distinção entre o método bancário e o método de formulação do problema - as primeiras teorias a temática do aprender diante de problemas. Conceituam, por fim, que aprender diante de problemas significa agir autonomamente no confronto com problemas de movimento (p.34 - 35).

Quanto à teoria e prática da oficina de movimento, Beckmann e Hildebrandt-Stramann, destacam logo de inicio o trabalho desenvolvido pelo professor alemão de ciências do esporte Landau que, se empenhou em implantar nas universidades as chamadas oficinas experimentais, cuja tarefa genuína é ocupar-se com mudanças e novas invenções, com a experimentação e a aplicação de projetos-modelos (p.45).

A partir disso, descrevem um cenário crítico-construtivo quanto à situação da vida cotidiana mediada por um mundo técnico com orientação ao consumo e, convidam aos leitores a refletirem sobre a urgência de se enfrentar estes problemas, que de certa forma, são estimulados no esporte pelo consumo, com novos estímulos e mercados (banhos vivenciais, férias no clube, bungee-jumping, rafting etc), enquanto a Educação Física estagna (p.46).

Neste cenário, apresentam o trabalho de oficina referindo-se às 'oficinas do futuro', desenvolvidas por Robert Jungk e Nobert Muller - que se dedicam à problemática do movimento no mundo contemporâneo(p.46) como um 'plano-modelo' que auxilie na formação de professores de Educação Física - com oficina focada no movimento - para que estes possam ter a oportunidade de aprender diferente e assim, ensinar na escola diferente. Com as palavras dos autores, serem ativos, pesquisando, desenvolvendo, inteiramente abertos, para depois poderem encenar a escola, ou seja, o ensino de movimento, de outra forma com crianças (p.47).

Mostrando alguns exemplos práticos com fotos de oficina de movimentos com criança (p.49 - 52) tanto na Alemanha, quanto no Brasil, os autores elucidam os objetivos e como podem ser desenvolvidas as aulas com 'oficinas de movimento'. Em síntese, descrevem três objetivos e três perspectivas para o desenvolvimento das oficinas, que são: 
Quanto aos objetivos: oportunizar as crianças a chance de configurar seu meio ambiente de movimento; favorecer a criança mais confiança em si mesma e segurança no movimentar-se por meio da vivência e realização dos planos e intenções de movimento; orientar à dialética entre o pensar e o fazer na ligação entre a construção e o movimento.

Quanto a desenvolver uma oficina de movimento: propor a gênese histórica de temas e idéias; refletir e agir sobre a construção e reconstrução de espaços e aparelhos de esporte e, desenvolver como nos diz os autores 'maluquices', que consiste no desenvolvimento criativo-utópico de temas de movimento (p. 52-55).

Por final, os autores destacam a oficina de movimento como laboratório pedagógico em que, alunos, estudantes e professores de Educação Física podem com situações diversas de movimento, construir e inventar aparelhos, estabelecer um processo continuo de aprendizagem e/ ou aperfeiçoamento profissional e, sempre estar entre o pensar e fazer ao aprender e descobrir o novo, isto é, aberta as experiências, ativa e criativamente, pesquisando e descobrindo (p.55).

\section{Educação Física fundamen- tada para/pelo movimento na perspectiva da 'Escola- Móvel'.}

No quinto capítulo Hildebrandt-Stramann caminha com uma proposta de 'Escola (s) em Movimento' que planeje uma educação em que o movimento seja um ponto de reflexão fundamental do processo didático-pedagógico escolar. Enfatiza conceitos, fundamentos, estruturas e projetos aplicados nas escolas da Alemanha e, descreve suas perspectivas com esta visão no Brasil.

Neste aspecto da obra, chamo a atenção, aos leitores que estejam interessados nas mudanças necessárias tanto, na formação, quanto, na atuação do Professor de Educação Física, especificamente na escola - tão esquecida - que, este

7 O professor Jürgen Dickert (Universidade de Oldenburg/Alemanha) em seus artigos e obras, publicados tanto no Brasil como na Alemanha, já denunciava desde a década de 70/80 até os dias atuais, a falta de interesse da maioria dos colegas brasileiros professores de Educação Física, quanto a estudos sobre jogos e movimentos, especialmente dos índios brasileiros, como também, das outras formas tradicionais de movimento da cultura brasileira, trazendo uma discussão a respeito do significado desses conhecimentos tanto para formação de professores de Educação Física como, além disso. 
projeto no Brasil apresenta-se como uma possibilidade concreta de se (re) ver, (re) agir e (re) direcionar as teorias e práticas também na perspectiva da cultura do movimento brasilei$\mathrm{ra}^{7}$. Como bem nos revela Dieckert (2004): todas as culturas da história humana tematizam 'o jogo e o movimento', considerando-os a Grécia e Roma, mas também o Egito e a China. Seria de estranhar se os índios brasileiros, que vivem em unidade com a natureza - e com isso também com a natureza de seus corpos - não tivessem desenvolvido uma cultura do movimento.(p.306).

Observar-se que Hildebrandt-Stramann dedica-se com profundidade na descrição das características da 'Escola em movimento' nesta obra. Inicia a discussão destacando a 'escola sem movimento' proferida por Paulo Freire que diz que imediatamente depois do Maternal, a criança de seis anos é 'parafusada' numa cadeira dura para estudar palavrórios durante horas e horas e, segue questionando, haverá melhor maneira de aprender a submissão?(p.57).

Posto isto, o autor apresenta duas posições sobre a Educação na Alemanha, uma que quer que a escola se concentre no encargo do ensino, principalmente na transmissão de conhecimentos, e outra que contradiz essa concepção, compreendendo a escola como 'centros de aprendizagem' em todas as dimensões disciplinares, ou seja, para além das disciplinas. Aqui, a escola é entendida, de acordo com a imagem-guia de Von Hentig (1993), como um espaço de experiência e de vida (p.58).

Mostra ainda que, os planos de ensino neste projeto de escola, distanciam-se do conceito de esporte performance, uma vez que neste plano é necessário configurar o esporte escolar e a Educação Física como 'Esporte Escolar Educativo' e 'Educação Física Educativa' - termos esses esclarecidos no capítulo um desta obra. Para tanto, a escola deve se propor a ser um espaço de movimento, em que não se pode restringir o jogo, o esporte e o movimento apenas à Educação Física, mas estendê-los a toda a escola. Trata-se de uma 'Escola Móvel teórica e prática (p.58).

Tendo por base a escola como um lugar para movimentar-se, o que é visto como um princípio geral na organização e configuração da escola (p.59), o autor com uma perspicácia didática, descreve com detalhes a imagem desta escola comparando-a como uma casa, onde o alicerce são seus dois elementos fundamentais: o movimento e desenvolvimento e, o movimento e aprendizagem. As paredes externas são o programa escolar. $\mathrm{O}$ teto simboliza a vida escolar e, os 
componentes de sua construção representam o conteúdo, composto por cinco temas essenciais: a sala de aula móvel, corpo e postura, aprendizagem interdisciplinar, oficina de movimento e, a educação do movimento aberta às experiências.

Para que esta 'Escola em Movimento', no entanto, ocorra, necessita-se pensar e agir no processo de formação do professor de Educação Física, o qual o autor preocupa-se nesta obra em descrever as capacidades e orientações básicas necessárias para ser professor neste ambiente escolar. Além de estimular à reflexão para uma transformação didático-pedagógica, ao descrever sua visão de um projeto de 'Escola em Movimento' conforme a realidade do cotidiano de vida das crianças, jovens e adultos brasileiros, exemplificando com fotos e modelos de aprendizagem já aplicados no Brasil - projeto em parceria com a professora Celi Taffarel (Universidade Federal da Bahia).

Constatando estas capacidades e orientações por intermédio de seus conhecimentos sobre a pedagogia e o desenvolvimento escolar ao longo de sua carreira, o autor ressalta que as mudanças cotidianas no trabalho escolar exigem qualificações como organizar, aconseIhar, cooperar, inovar e avaliar[...] que tem haver com a organização social interna da escola (p.68). Des- taca ainda, que os professores de Educação Física devem na prática realizar suas capacidades de inovação e cooperação, tanto entrem si, quanto com os professores de outras disciplinas e áreas de aprendizagem - com isto evitam a questão do isolamento. Além disso, também devem documentar os processos de investigação através de métodos adequados de seleção e de análise de dados. Os processos de avaliação aqui utilizados baseiam-se no conceito teórico da pesquisa-ação por Altrichte\& Posch (p.69).

Posto isto, é imprescindível saber que uma escola só entra em movimento se os professores entrarem em movimento internamente (p.69). Isto significa pensar nas capacidades que os professores de Educação Física necessitam, devendo estas ser discutidas como um dos temas didático-pedagógico no processo de formação deste professor. $\mathrm{O}$ autor cita a exemplo, sua experiência quanto a esta realização em conjunto com os estudantes e professores na Alemanha, concluindo que para o alcance deste objetivo necessita-se das seguintes capacidades: adquirir conhecimentos através da literatura científicopedagógica; inovação ligada a um conhecimento específico; cooperação e, avaliação.

O autor nos oportuniza, com sua visão didático-pedagógica, 
uma possibilidade de se configurar uma 'Escola em Movimento' no Brasil pelo processo de formação de professores de Educação Física, mediante três visões de escola:

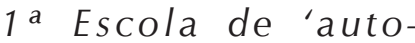
cuidado'corporal. O autor considera a situação de ordem política e social como componentes desta proposta de escola, cita a exemplo: o comer e beber como meios de viver, o lidar com luz, ar eágua, organizar-se com os outros etc.

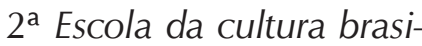
leira de movimento. O autor, não só, denuncia que atualmente a riqueza das formas tradicionais de movimento da cultura brasileira é pouco estudada, mas também destaca, a importância de sua integração na escola como uma forma de 'reconscientização' dos próprios valores culturais, cita a exemplo as formas de jogo e dança da capoeira e, o frevo.

$3^{a}$ Escola da vizinhaça e de produção. $\mathrm{O}$ autor destaca seu aprendizado neste tipo de escola com a professora brasileira Celi Taffarel, realizados geralmente nos bairros pobres e nas favelas do Brasil, que na prática significa que as escolas se tornem 'escolas da vizinhança e de produção' (p.72) que evidentemente, está entrelaçada com o contexto histórico, econômi$\mathrm{co}$, ambiental e social, cita a exemplo planos de ensino direcionados a : como superar doenças, como se organizar, como viver com o lixo e do lixo etc.

Ainda neste contexto, o autor descreve os módulos de ensino que propicia aos estudantes as competências para construção de tais escolas, que em síntese são: 'escola móvel como escola de produção e abertura à coletividade; 'teoria e prática da cultura brasileira de movimento'; movimento e 'autocuidado corporal'; conceitos referentes ao relacionamento entre educação, movimento, desenvolvimento e configuração da escola; o aprender em oficinas de movimento e, oficina de pesquisa (p.74).

Aqui, convido os leitores a refletir uma questão proposta, consoante as três visões e os módulos sinteticamente acima descritos nesta obra. Qual deve ser o objetivo e os conteúdos da Educação Física na Escola Brasileira? Teria que assumir o autocuidado, ter o significado de uma cultura de movimento brasileira e participar da vizinhança e produção nas ações didáticopedagógico? Seria o de plantar Cultura, cidadania e saúde ${ }^{8}$ ? Precisaria

8 Slogan do lançamento da Campanha Nacional do CONFEF (Conselho Federal de Educação Física) que elegeu o ano de 2009, como o 'Ano da Educação Física Escolar: Plantando Cultura, Cidadania e Saúde'. 
aplicar uma transformação didáticopedagógica do esporte ${ }^{9}$ ?

No caminhar de um debate sobre esta simples questão reflexiva, pode-se encontrar na obra de Hildebrandt-Stramann, especialmente neste quinto capítulo e, no oitavo - em que o autor nos traz temas centrais descritos com profundidade, com referenciais teóricos e propostas pedagógicas postas na prática - uma base de realizações concretas para este contexto da Educação Física Escolar Brasileira, há muito desvalorizada.

\section{Educação Física contribuindo com uma relação de domínio (esporte) ou de parceria (mo- vimentar-se) entre o homem e a natureza?}

Para captar o processo de mudança no relacionamento do homem com a natureza e sua evolução de uma relação de parceria à de domínio, o autor no capitulo seis, descreve esta relação no contexto esportivo, com suas conseqüências e possibilidades de parceria, por meio de cinco Teses.

Inicia sua primeira Tese discorrendo sobre o estreito contato do homem com a natureza até sua moderna relação de separação com a mesma. Salienta nesta trágica mudança, conseqüências que afetam não somente a natureza externa, em torno de nós, mas também a natureza interna do homem - a corpórea (p.78).

$\mathrm{Na}$ segunda Tese, o esporte é descrito pelo autor como exemplo clássico para dominação da natureza pelo homem (p.79$81)$. Em outras palavras, o atual modelo de esporte forma um ideário de aprendizagem e formas de praticas pedagógicas baseadas na perspectiva analítica do corpo fisiológico e funcional, configurado por regras - tanto no espaço-tempo, quanto biomecânicos - que "prometem" o movimento ideal e seu controle por aparatos tecnológicos, enquanto que, os alunos - "corpo -objeto" e, não "corpo - sujeito" devem reproduzir os movimentos verbalizados pelo professor como "certos", ou seja, a aprendizagem do movimento não é mais assunto do aluno, mas sim do professor. $O$ aluno está alheio ao seu movimento e, conseqüentemente, ao seu corpo. Ele é um objeto, no qual deve ser implantada uma forma estranha de movimento (p. 81).

Sobre a terceira Tese reversibilidade da relação homem-

9 Proposta elaborada por Elenor Kunz para a Educação Física Escolar centrada no ensino dos Esportes. 
natureza, lembra Hildebrandt-Stramann que por um lado, ela parece irreversível - quando a natureza é vista para o esporte como espaço de movimento trabalhada e modificada no sentido de rigor da matéria técnica (p.81) bem como, quando o corpo humano é tratado somente como meio de funcionalização e tratamento técnico-sistemático (p.81), especialmente no ambiente do esporte de alto rendimento e no fitness. Por outro lado, considera sua possibilidade de reversibilidade, quando pela configuração 'paradigmática' de visão de mundo - que tem se esforçado por uma relação de 'parceria' - se conciliar novamente a apropriação da natureza e sua conservação como coesão ordenada (p.81).

Ao final desta parte, o autor relata em sua quarta Tese, um paradigma ecológico-humano capaz da dialética, de entrelaçar e, de reconhecer o pensar e agir como sinergético para uma educação de autonomia e responsabilidade, citando alguns projetos seus já realizados na práxis com esta base teórica, a exemplo: a cidade como espaço de movimento; o jardim de infância e a Escola Móvel, o movimento aberto à experiência para Educação Física. (p.83-87 etc).

Com esta perspectiva, Hildebrandt-Stramann, em sua quinta e última Tese, descreve justificativas para uma pedagogia humana de movimento por esta buscar conciliar a relação ente o homem e a natureza (p.87). Para tanto, trata desta questão, limitando suas justificativas em três pontos de vista:

$1^{\circ}$ Antropológico - afirma a existência de 'déficits' no desenvolvimento infantil, quando as relações do homem com sua natureza interna e externa são interpeladas. $E$, revela a concepção de homem como homo ecologicus, que concebe viver ao mesmo tempo consigo mesmo e com as coisas e seres vivos ao seu redor (p.87);

$2^{\circ}$. Sensitivo-Estética - em que o movimento é o meio para se atingir muitos sentidos, isto pode ser experimentado, em encontros multisensitivos, diretamente ligados ao meio ambiente, destacando que segurança e consciência são duas das principais tarefas de uma educação de movimento na escola (p.87).

$3^{\circ}$. Pedagógico - cita a justificativa histórica e educativa descrita no romance de Émille, de Rousseu - que descreve uma variedade de combinações entre a educação de movimento e encontros com a natureza - como uma teoria já pensada nos temas que tratam a natureza no contexto da educação e formação. Com isto, destaca que tudo que o homem compreende, só 
o compreende pelos sentidos [...] em que se deve chegar a conhecer mais o valor próprio da natureza do que seu valor utilitário (p.88).

\section{Educação Física discutindo formas didático-metodológi- cas para formação de seus professores.}

Depois de analisar o esporte e o movimento no contexto das relações entre o homem e a natureza, o autor descreve em seu sétimo capítulo, não só o plano de formação dos professores de Educação Física da Universidade de Braunschweig na Alemanha, mas também, cita um projeto de nova grade curricular desenvolvido na Universidade da Bahia com a professora Celi Taffrel entre 2006-2008 no Brasil e, segue narrando quatro pontos centrais deste processo de formação na Alemanha, que são:

$1^{\circ}$ Mudança do paradigma esportivo para um paradigma de "movimentar-se".

$2^{\circ}$ Mudança sobre os conceitos teóricos e práticos, de uma visão científica natural para uma visão pedagógica do movimento.

$3^{\circ}$ Mudança da formação prática, das disciplinas esportivas para campos de aprendizagem e de experiência.

$4^{\circ}$ Ampliação da tarefa do "movimentar-se" das aulas de
Educação Física, até se constituir uma Escola Móvel.

Diferentemente, portanto, das 'tradicionais' grades curriculares, diretrizes e, planos de ensino, propostas pela maioria dos cursos de Educação Física no Brasil, o autor nos mostra uma possibilidade de se pensar este caminho do processo de formação de professores de Educação Física, com uma proposta ousada. Tal proposta se orienta por uma filosofia e pedagogia - que norteiam a constituição dos objetivos, "campos-problema", campos de aprendizagem e de experiências (os estudantes podem optar por cinco campos com uma carga horária de quatorze horas) etc - baseada em três Teses:

$1^{\text {a }}$ Concepção pedagógica moderna - que é a concepção de aulas abertas às experiências, onde os estudantes devem compreender os conceitos de educação (autoeducação), de movimento (capacidade de descobrir o significado do movimentar-se), de ensino (como um processo comunicativo entre professor e aluno) e, de escola (como um lugar de movimentar-se).

$2^{a}$ Capacidade didático-metodológica transformadora (existem na Alemanha diferentes concepções que seguem este paradigma transformador) - onde os estudantes devem conhecer 
métodos que permitam uma transformação didática dos conteúdos pelos próprios alunos, isto é, devem ter a capacidade transformadora de como um conteúdo esportivo pode ser transformado, metodologicamente, em conteúdo que permita aos alunos desenvolverem e realizarem seus próprios significados de movimento, ao contrário da prática tradicional, em que a aprendizagem motora deve ser configurada para levar o aprendiz mais rapidamente e de forma efetiva para um movimento esportivo (p. 98-99).

$3^{\text {a }}$ Processo de socialização na formação, do esportista para um educador do movimento - onde no estágio os estudantes (em sua maioria esportistas) passam por um processo de transformação da sua consciência por meio de três fases (p.100-101):

$1^{\text {a }}$ Fase: preparatória (seminário com o tema: Análise das biografias dos estudantes);

$2^{\text {a }}$ Fase: distanciar-se das próprias 'experiências bibliográficas' denominada, analisar e planejar a forma de atuar na reconstrução didática do ensino, sendo característico nesta fase os 'trabalhos de oficina' e,

$3^{\text {a }}$ Fase: desenvolvem seus planos nas escolas públicas, denominada, desenvolvimento e avaliação das aulas de Educação Física..

\section{Educação Física configurada no processo de envelheci- mento: o indubitável valor do movimentar-se na perspectiva da saúde salutogenética.}

$$
\text { Um verdadeiro desafio }
$$
fica evidente na oitava e ultima parte desta obra: Ter postura para uma 'nova fase da vida' o qual, Hildebrandt-Stramann o descreve em conjunto com dois professores brasileiros: a professora Vera Costa (Universidade Federal do Rio Grande do Norte) e o professor Amauri Oliveira (Universidade Estadual de Maringá). Desafio por trazer o 'movimentar-se' como novo paradigma no contexto da saúde, compreendendo-o com muitas funções e não somente a esportiva. É importante lembrar aqui também, o significado proposto pelos autores da palavra 'postura' em dois sentidos: por um lado de atitude corporal, uma pessoa que gosta de movimentar-se e, por outro lado, dignidade, consciência do seu valor, autonomia (p.103).

Assim, tendo em vista o crescente aumento da população idosa em nível mundial, os autores discutem esta temática em torno do conceito de saúde e da compreensão de movimento e corpo numa definição de saúde salutogenética, bem como, preocupam-se em 
exemplificar estes conceitos na prática, com dois exemplos para uma proposta de movimento salutogenética. Nesta perspectiva, revelam as mudanças nas Ciências da Saúde sobre a compreensão da saúde, saindo de uma visão patogenética, para uma visão salutogenética, isto é, não é mais o que faz uma pessoa adoecer, mas, sim, o que faz a pessoa se manter sadia (p.105-106).

Partindo deste conceito, denunciam que uma compreensão do biológico-funcional de saúde e de movimento torna-se muito limitada, tendo na perspectiva do movimentarse uma ampliação, que em suma, relaciona-se com a saúde por contribuir na manutenção e melhoramento da capacidade física, psíquica e social; na manutenção, restabelecimento e melhoramento da capacidade de função biológica e no desenvolvimento de uma capacidade de realização individual (p.107).

$E$ ainda, revelam nesta perspectiva que, o 'segredo'da saúde consiste em conseguir harmonizar o querer, o poder e o dever, ou seja, aquilo que se quer com o que ainda se pode e aquilo que se deve.(p.109). Logo, torna-se evidente, o importante papel do corpo e movimento para atingir este intento, à medida que o corpo representa a linha de contato entre $o$ eu e o meio ambiente e, com isto, todos os modelos de conduta aprendidos e interiorizados durante a vida são memorizados no corpo e requeridos através dele e, pelo movimento, esses modelos podem tornar-se conscientes (p.109).

\section{Educação Física aos que que- rem 'transformar'...}

Fica evidente que esta obra de Hildebrandt-Stramann, que já publicou outros livros no Brasil, descreve não somente teorias e práticas acessíveis no seu "ambiente alemão", mas também, possível e já transformadas para o "ambiente brasileiro". Confirmar-se isto, mediante o trabalho desenvolvido entre este autor e a professora Celi Taffarel, a exemplo, os projetos elaborados e executados sobre currículo (Taffarel, C. e Hildebrandt-Stramann, 2007) no processo de formação dos professores de Educação Física. Também se pode perceber isto, quanto ao que o autor e a Editora quiseram mostrar com a capa desta obra: realizações de uma Educação Física aberta à experiência não só em "solo" alemão, mas principalmente em "solo" brasileiro.

A forma como HildebrantStramann e os demais autores descreve esta obra, facilita sua compreensão e estimula ao desafio na práxis desta discussão didáticopedagógica, que trata de modo geral dos rumos da Educação Física no 
contexto educacional e da saúde, tendo por base a experiência na perspectiva do movimentar-se no cotidiano de vida. Não há 'criticas', há, sobretudo, um desejo de trabaIhar para que estas discussões estejam no cotidiano das universidades e escolas brasileiras. Sendo a obra deste autor, sem dúvida, mais uma ferramenta pelo que o leitor possa aprofundar suas reflexões sobre os 'novos paradigmas' existentes na área da Educação Física.

Com o intuito de contribuir com estas discussões, mantevese aqui um breve diálogo entre a obra deste autor e, o pensar sobre a era da "sociedade do conhecimento e da comunicação" (que se comporta como uma sociedade da 'incomunicação e isolação', imbricada no 'mundo virtual') como ponto de relação necessária aos que querem transformar, tanto o processo de formação, quanto a atuação dos professores de Educação Física. Diálogo este interdependente nesta 'sociedade', tão 'carente' de manifestações que orientem o movimentar-se na amplitude de suas complexas funções no 'mundo' da realidade da vida cotidiana.

Por fim, este livro é indicado para todos aqueles professores que possuem em seu coração, a vontade de transformar, com suas percepções e movimento pro-ativo (corpo-sujeito- ativo) para uma so- ciedade com 'postura' critica em face da existência destes dois 'mundos' (virtual e da vida) que são interdependentes do ambiente de formação escolar e universitário, que oriente a um 'Ser' humano autônomo, que pense em suas responsabilidades com ações na práxis perante si, os outros e o meio ambiente ao seu redor.

\section{Referências}

BERGER, P.L. \& LUCKMANN, T. A construção social da realidade: tratado de sociologia do conhecimento. Traduzido por: Floriano de Souza Fernandes. Petrópolis: Vozes, 2005.

BOFF, L. Saber cuidar: ética do humano - compaixão pela terra. 14ed. Petrópolis, RJ: Vozes, 2008.

DIECKERT, J. Esporte e Cultura: pode a tradicional cultura do movimento brasileira ser considerada como uma perspectiva para a formação de professores de Educação Física no Brasil? In: KUNZ,E \& HILDEBRANDT-STRAMANN, R.(orgs). Intercâmbios científicos internacionais em educação física e esportes.ljuí: Ed.Unijuí, 2004.

LEFF, E. Saber Ambiental: sustentabilidade, racionalidade, 
complexidade, poder. Traduzido por: Lúcia Mathilde Endlich Orth. Petrópolis, RJ: Vozes, 2001.

TAFFAREL, C.Z; e HILDEBRANDTSTRAMANN, R. (orgs.) Currículo e Educação Física: formação de professores e prática pedagógica nas escolas. ljuí: Ed. Unijuí, 2007.

Recebido: 07/fevereiro/2010. Aprovado: 12/abril/2010. 